\title{
Single dose antibiotic prophylaxis in elective obstetric and gynaecological surgeries-a descriptive study
}

\author{
Jayanthi Mohan, Thangaroja T., Maya Menon*
}

Department of Obstetrics and Gynecology, ESIC Medical College and PGIMSR, KK Nagar, Chennai, Tamil Nadu, India

Received: 21 June 2017

Accepted: 19 July 2017

*Correspondence:

Dr. Maya Menon,

E-mail: jayanthimohan2000@gmail.com

Copyright: () the author(s), publisher and licensee Medip Academy. This is an open-access article distributed under the terms of the Creative Commons Attribution Non-Commercial License, which permits unrestricted non-commercial use, distribution, and reproduction in any medium, provided the original work is properly cited.

\begin{abstract}
Background: Wound infection is a common complication of obstetric and gynaecological surgeries. It is not clear whether single dose perioperative prophylaxis with antibiotics is sufficient to prevent wound infections. This study was conducted to assess whether perioperative single dose antibiotic is effective in preventing post-operative infections in women undergoing elective obstetric and gynaecological surgeries.

Methods: Participants were administered a single dose of $1 \mathrm{gm}$ Cefotaxime intravenously before obstetric and gynecological surgery and followed up for the incidence of post-operative complications such as wound infections, wound resuturing etc.

Results: Study included 154 electives obstetric and gynecologic cases. 86 were obstetric cases and 68 were gynecologic surgeries. For gynecologic surgeries Cefotaxime injection 1g IV was given 30 minutes before surgery and for obstetric surgeries the same was given after cord clamping. Incidence of febrile morbidity was $5.8 \%$ in obstetric cases and $10.3 \%$ in gynecologic cases. Incidence of wound infection was $2.32 \%$ in obstetric cases and $1.47 \%$ in gynecologic cases. Three cases had wound infection, the organisms isolated in wound infection were $E$. coli, Pseudomonas, Methicillin resistant staphylococcus which were sensitive to cefoperazone-sulbactum and linezolid. The mean duration of hospital stay was 8.2 days in obstetric and 8.03 days for gynecologic patients.

Conclusions: Single dose Cefotaxime prophylaxis is equally effective compared to conventional multi-dose antibiotic therapy. It is cost effective and safe for both obstetric and gynecological surgeries.
\end{abstract}

Keywords: Elective surgeries, Single dose antibiotic, Prophylaxis, Wound infection

\section{INTRODUCTION}

Prophylactic antibiotics in surgery is intended to prevent morbidity, mortality as well as to reduce the duration and the cost of hospitalization. ${ }^{1}$ Prophylactic antibiotics are helpful in preventing post-operative infection. Single dose prophylaxis can help in reduction of development of microorganism resistance. ${ }^{2}$ Studies have proved the efficacy of antibiotic prophylaxis in preventing surgical infections. Single dose prophylaxis has not been accepted and multiple dose regimens are still used in many centres. $^{3-6}$ Perioperative antimicrobial prophylaxis has been advocated in surgical procedures, but recent guidelines and publications showed that single dose antibiotic prophylaxis is equally effective in clean, and clean contaminated surgical procedures., ${ }^{7,8}$ Antibiotic prophylaxis refers to a very brief course of an antibiotic initiated just before the surgery. Improvement of aseptic and surgical techniques and use of antibiotics as prophylaxis resulted in reduction of postoperative wound infections. Caesarean deliveries are more prone to wound infections as compared to deliveries vaginally. ${ }^{9,10}$ In a 
Canadian retrospective study using national database, data reviewed from 1991 to 2005 for planned caesarean sections versus vaginal delivery showed the rate of severe morbidity as 27.3 and 9.0 per 1000 deliveries, respectively. Febrile morbidity is frequent after caesarean delivery. ${ }^{11}$ Numerous good-quality trials have proved that that a single dose of an antimicrobial agent given at the time of caesarean delivery significantly decreases infectious morbidity. ${ }^{12-16}$ Although more obvious for women undergoing unscheduled caesarean delivery, this practice also significantly lowers the postoperative infection rate in women undergoing elective surgery. A 2010 Cochrane review found that routine antibiotic prophylaxis for caesarean section (in both elective and non-elective settings) is effective in reducing surgical site infection (relative risk (RR) for wound infection 0.39 ; $95 \%$ confidence interval (CI) $0.32-0.48$ ) and the analysis included 77 studies and 11971 women. ${ }^{17}$ The timing of antibiotic prophylaxis was not specifically addressed in the review. ${ }^{18}$ Surgical antimicrobial prophylaxis refers to a very short course of an antimicrobial agent initiated just before an operation begins. ${ }^{19-22}$ Antimicrobial prophylaxis is an attempt to not sterilize tissues, but a critically timed adjunct used to decrease the microbial burden of intraoperative contamination to a level that cannot overwhelm host immunity. Administered by the IV route the initial dose of antimicrobial prophylactic agent, is timed such that a bactericidal concentration of the drug is established in serum and at tissue level when the incision is made, maintaining therapeutic levels of the antimicrobial agent in serum and tissue level throughout the operation and until, at the most, a few hours after the incision is closed in the operating room. ${ }^{23-25}$ So, prophylactic antibiotics is not meant to cover every possible pathogen that may cause infection. By reducing the number of organisms' present (the bacterial load) it will enable the patient's immunological defences to function adequately. ${ }^{26}$

Antibiotics administered prior to skin incision may further reduce the risk of postoperative infection. Antibiotics need to be present adequately in the tissue at the time of incision to be effective. postoperative antimicrobial prophylaxis is unnecessary as it increases cost and causes drug resistance with resistant bacteria. ${ }^{27}$

There is insufficient evidence concerning timing of administration (preoperative versus after cord clamping) of antibiotic prophylaxis for caesarean section. Nearly all published trials since 1978 have administered the antimicrobial drug immediately after the cord is clamped. Prior to this, prophylactic agents were administered preoperatively. ${ }^{28}$ This abrupt change in practice followed the publication of prospective randomized placebo controlled trial demonstrating that prophylactic ampicillin administered after the umbilical cord was clamped was as effective in decreasing maternal morbidity as ampicillin given before to the procedure. At the time of hysterectomy, vaginal or cervical bacteria are inoculated into the surgical site, and it is hypothesized that antimicrobial agent in these tissues at that time augment host defence mechanisms to reduce the incidence of clinical infections. For an antibiotic prophylaxis to function effectively, several important criteria must be fulfilled. First, the operative procedure must have a significant risk of bacterial contamination and, in the absence of prophylactic antibiotics, an appreciable incidence of operative site infection. Secondly, the prophylactic antibiotic administered should be effective against expected pathogens and have a low rate of side effects. Thirdly, the antibiotic should not be one that would be routinely used therapeutically. Although many antibiotic regimens have proven effective in prospective, randomized trials for gynaecological surgery, the cephalosporins have emerged as the generally recommended antibiotic because of their effectiveness, low incidence of side effects, and low cost. ${ }^{29}$ Finally, for effective antibiotic prophylaxis, the tissue levels of the chosen antibiotic need to be optimal at the time bacterial contamination of the surgical site occurs. This means that the antibiotic needs to be administered shortly before the start of surgery. However, there remains a lot of confusion about the efficacy of a single dose antibiotic prophylaxis prior to elective obstetrics and gynaecology surgery. ${ }^{30}$ This study was conducted to evaluate the effectiveness of single dose antibiotic prophylaxis in elective obstetric and gynaecological surgeries.

\section{METHODS}

The study was conducted as a descriptive cross-sectional design. Baseline assessment including vital signs, general physical, systemic and gynecological examination were performed and then routine blood (CBC, RBS, RFT) and urine analysis, urine culture and sensitivity, high vaginal swab culture and sensitivity were carried out.

\section{Inclusion criteria}

- Patients who undergo elective abdominal hysterectomy, vaginal hysterectomy,

- Diagnostic and operative laparoscopy,

- Laparotomy for ovarian cystectomy,

- Elective caesarean section of booked cases.

\section{Exclusion criteria}

- Women who had known or suspected hypersensitivity to cephalosporins

- Any co-existing diseases like diabetes mellitus, hypertension or cardiac problem that will require multi dose antibiotics

- In obstetric- un booked cases, patients with premature rupture of membranes, GDM, Anaemia, PIH, Heart diseases.

Written informed consent was obtained from all participants. Within 24 hours prior to surgery baseline assessment including vital signs, general condition, systemic and gynecological examinations were performed. Routine blood investigations (CBC, RBS, and 
RFT) and urine routine analysis, urine culture and sensitivity, high vaginal swab culture and sensitivity were performed. Cefotaxime single dose $1 \mathrm{~g}$ intravenous (after test dose) was given 30minutes before incision in gynecological surgeries and after cord clamping in caesarean section. If the surgical procedure exceeded more than 3 hours and if blood loss was more than $1500 \mathrm{ml}$ an additional dose of prophylactic antibiotic was given 3-4hours after initial dose (ACOG guidelines). During post op period 4th hourly temperature monitoring, vital signs, abdominal, perineal examinations was performed daily till 7days. If body temperature was more than $1010 \mathrm{~F}$ on 2 occasions 4 hours or more apart, excluding the night of surgery, it was considered as febrile morbidity and appropriate investigations were performed including urine culture, blood culture, high vaginal swab culture before starting appropriate multi dose antibiotics. Wound was inspected for superficial or deep infection, any pus discharge, surgical site abscess formation, wound dehiscence, vault haematoma and pelvic abscess. At discharge, patients were instructed to contact if they have any signs and symptoms of infection. All patients were followed up to 3 months at monthly intervals.

Primary outcome: Incidence of postoperative morbidity (febrile morbidity and infectious morbidity such as wound infection, chest infection, UTI, pelvic abscess and dehiscence of scar)

\section{Statistical analysis}

The sample size was calculated to estimate the incidence of wound infections with a $95 \%$ confidence level and $10 \%$ precision. The required sample size was 152(calculated by using nMaster software-version 1.0). Statistical analysis was performed using SPSS statistical package version 21 .

\section{RESULTS}

Table 1: Post-operative complications among the study participants.

\begin{tabular}{|c|c|c|c|c|c|c|}
\hline \multirow[t]{2}{*}{ Complication } & \multicolumn{2}{|c|}{$\begin{array}{l}\text { OBS. } \\
\text { Patients }\end{array}$} & \multicolumn{2}{|c|}{$\begin{array}{l}\text { Gynaec. } \\
\text { Patients }\end{array}$} & \multicolumn{2}{|c|}{ Total } \\
\hline & $\mathbf{N}$ & $\%$ & $\mathbf{N}$ & $\%$ & $\mathbf{N}$ & $\%$ \\
\hline Fever & 5 & 5.81 & 7 & 10.29 & 12 & 7.79 \\
\hline Wound Infection & 2 & 2.33 & 1 & 1.47 & 3 & 1.95 \\
\hline $\begin{array}{l}\text { Wound } \\
\text { Resuturing }\end{array}$ & 2 & 2.33 & 1 & 1.47 & 3 & 1.95 \\
\hline $\begin{array}{l}\text { Urinary Tract } \\
\text { Infection }\end{array}$ & 0 & 0 & 0 & 0 & 0 & 0 \\
\hline $\begin{array}{l}\text { Respiratory Tract } \\
\text { Infection }\end{array}$ & 0 & 0 & 0 & 0 & 0 & 0 \\
\hline
\end{tabular}

Table 1 shows the incidence of postoperative complications in both the obstetrics and gynaecology patients. It is seen that postoperative fever was higher among the gynaecological surgery patients compared to the obstetric surgery patients.

Extra dose of antibiotics was required in only $0.65 \%$ of the participants. Wound infection occurred in only $1.94 \%$ of the participants. The mean duration of hospital stay was 8.12 days.

It was seen that the obstetric patients were predominantly in the age group of 21-30 years whereas the gynaecology patients were in the age group of 31-50 years. This is shown in Table 2.

Table 2: Age comparison of obstetrics and gynecology patients.

\begin{tabular}{|lllllll|}
\hline \multirow{2}{*}{$\begin{array}{l}\text { Age (in } \\
\text { years) }\end{array}$} & \multicolumn{2}{l}{$\begin{array}{l}\text { Obs. } \\
\text { patients }\end{array}$} & \multicolumn{2}{l}{$\begin{array}{l}\text { Gynec. } \\
\text { patients }\end{array}$} & \multicolumn{2}{l|}{ Total } \\
\hline $21-30$ & 66 & 76.74 & 5 & 7.35 & 71 & 46.10 \\
\hline $31-40$ & 20 & 23.26 & 23 & 33.82 & 43 & 27.92 \\
\hline $41-50$ & 0 & 0 & 32 & 47.06 & 32 & 20.78 \\
\hline $51-60$ & 0 & 0 & 4 & 5.88 & 4 & 2.60 \\
\hline $61-70$ & 0 & 0 & 4 & 5.88 & 4 & 2.60 \\
\hline Total & 86 & 100 & 68 & 100 & 154 & 100 \\
\hline
\end{tabular}

The types of surgeries that the study participants underwent is shown in Table 3. It is seen that more than $50 \%$ of the surgeries were LSCS with about $26 \%$ being abdominal hysterectomy.

Table 3: Types of surgery in the study participants.

\begin{tabular}{|lll|}
\hline Surgery & Number & $\%$ \\
\hline $\begin{array}{l}\text { Lower segment caesarean } \\
\text { section }\end{array}$ & 86 & 55.84 \\
\hline Abdominal Hysterectomy & 41 & 26.63 \\
\hline Vaginal Hysterectomy & 9 & 5.84 \\
\hline Laparotomy & 15 & 9.74 \\
\hline Laparoscopy & 3 & 1.95 \\
\hline Total & 154 & 100 \\
\hline
\end{tabular}

Among the obstetric surgical patients, a majority lost between 200-300 $\mathrm{ml}$ of blood and among the gynaecology patients, a majority lost about $300-400 \mathrm{ml}$ of blood during surgery. Blood loss is depicted in Table 4.

Table 4: Blood loss in the study participants.

\begin{tabular}{|lllllll|}
\hline & \multicolumn{2}{l}{$\begin{array}{l}\text { Obs. } \\
\text { patients }\end{array}$} & \multicolumn{2}{l}{$\begin{array}{l}\text { Gynec. } \\
\text { patients }\end{array}$} & \multicolumn{2}{l|}{ Total } \\
& $\mathbf{N}$ & $\mathbf{\%}$ & $\mathbf{N}$ & $\mathbf{\%}$ & $\mathbf{N}$ & $\mathbf{\%}$ \\
\hline$<50 \mathrm{ml}$ & 0 & 0 & 6 & 8.82 & 6 & 3.90 \\
\hline $50-100$ & 0 & 0 & 5 & 7.35 & 5 & 3.25 \\
\hline $100-200$ & 9 & 10.46 & 8 & 11.76 & 17 & 11.04 \\
\hline $200-300$ & 57 & 66.28 & 17 & 25.00 & 74 & 48.06 \\
\hline $300-400$ & 20 & 23.26 & 32 & 47.06 & 52 & 33.77 \\
\hline Total & 86 & 100 & 68 & 100 & 154 & 100 \\
\hline
\end{tabular}


The mean duration of obstetric surgery was 74 mins and the mean duration of gynaecologic surgery was 112 mins. This is shown in Table 5 .

Table 5: Duration of surgery of study participants.

\begin{tabular}{|llll|}
\hline Mean & Obs. patients & Gynec. patients & Total \\
\hline SD & 74.59 & 112.43 & 91.30 \\
\hline Minimum & 13.49 & 38.67 & 33.33 \\
\hline Maximum & 50 & 30 & 30 \\
\hline
\end{tabular}

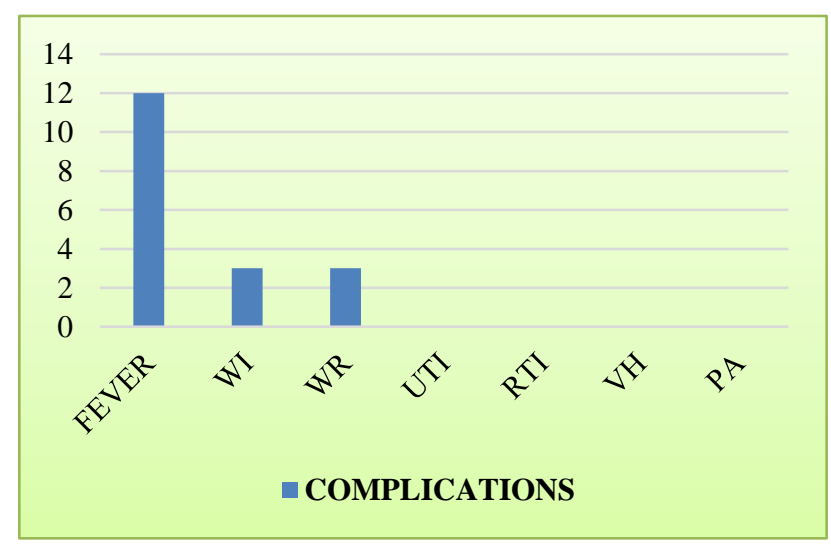

Figure 1: Complication present.

\section{DISCUSSION}

The primary aim of prophylactic antibiotics is to reduce the infection and thereby reduce morbidity and mortality. Antibiotic prophylaxis for caesarean section and gynaecologic surgeries should be perioperative, ensuring a high plasma concentration of antibiotic during the operation. Various recent studies in obstetric cases proved that there is definite role of prophylactic antibiotics. Many antibiotics are used in various combinations, single dose or multiple dose regimes given preoperatively or over the course of several days. Many studies showed that proper and timely administered prophylactic antibiotic can prevent postoperative infection.

Wound infection is an important postoperative complication. It is associated with readmission in hospital, repeat surgery or intervention, prolonged hospital stays and significant clinical and economic consequences.

Out of 154 patients 86 patients were obstetric patients, 68 patients were gynecologic patients. In patients who underwent caesarean section, previous LSCS was the most common indication accounts about $93 \% .83$ patients were multipara and only 3 patients were primigravida, of those primigravida 2 patients undergone caesarean section for the indication breech and 1 patient for cephalopelvic disproportion. The mean age was 28 . The mean duration of surgery was 74.59 minutes. The mean blood loss was $291.28 \mathrm{ml}$. The mean duration of hospital stay was 8.2 days. Five patients had fever in patients who underwent caesarean section so febrile morbidity accounts for about $5.8 \%$ in caesarean patients. Those patients were investigated, blood samples were sent for CBC, Peripheral smear for MP, MF, Dengue NS1, urine microscopy, urine culture and sensitivity, high vaginal swab for culture and sensitivity. The investigations were normal in those patients. Because of the fever started on multi dose antibiotics with Cefotaxime 1g IV BD and metronidazole $500 \mathrm{mg}$ IV TDS given for 5 days. In those patient's suture removal was done on 8th postoperative day and there was no wound infection.

Two patients had wound infection on $5^{\text {th }}$ and $8^{\text {th }}$ postoperative day, so swab for culture and sensitivity taken from the wound discharge. Appropriate antibiotics were given according to culture and sensitivity report. In one patient with wound infection methicillin resistant staphylococcus grown which was sensitive to linezolid and that patient was started on linezolid $600 \mathrm{mg}$ BD and given for 7 days. Wound resuturing was done on $12^{\text {th }}$ postoperative day and discharged $16^{\text {th }}$ postoperative day. The other patient in LSCS group had wound discharge on $5^{\text {th }}$ postoperative day, from the wound swab pseudomonas organism growth identified which was sensitive to cefoperazone-sulbactam. That patient was treated with cefoperazone-sulbactam 1g IV BD for 7 days. Resuturing was done on $13^{\text {th }}$ postoperative day and discharged on $17^{\text {th }}$ postoperative day.

Total number of gynecologic surgeries was 68 , of which total abdominal hysterectomy was 41, vaginal hysterectomy 9, laparotomy 15, and laparoscopy were 3 . The most common indication for which abdominal hysterectomy was performed for fibroid uterus accounts for about $68.3 \%$. The next common indication were adenomyosis and abnormal uterine bleeding accounting for about $12.2 \%$. Vaginal hysterectomy done for prolapse uterus was 9. laparotomy performed for ovarian and para ovarian cyst were15.Number of laparoscopies performed for diagnostic purpose in infertility patients were 3 . Mean duration of surgery was 112.43 minutes. Mean blood loss was $275.88 \mathrm{ml}$. Mean duration of hospital stay was 8.03 days. Out of total gynecologic surgeries only one patient had wound infection on $7^{\text {th }}$ postoperative day. The organism isolated from wound swab was $E$. coli sensitive to cefoperazone-sulbactam. Patient was treated with the same for 7 days. Wound resuturing was done on $17^{\text {th }}$ postoperative day and the total duration of hospital stay was 21 days.

The mean age was 34.58years in total patients undergone surgery with the standard deviation of 9.59. The mean body mass index was 22.7 in total patients undergone surgery with the standard deviation of 1.44 . The mean blood loss was $284.48 \mathrm{ml}$ including both obstetric and gynaecologic cases with the standard deviation of 84.52 . The mean duration surgery was 91.3 minutes in total patients undergone surgery with the standard deviation of 33.33. Mean hospital stay was 8.12 days including both 
obstetric and gynaecologic cases with the standard deviation of 1.49 . Febrile morbidity accounts for $7.8 \%$ and wound infection accounts for $1.95 \%$ in total patients undergone surgery. In obstetric patients $2.32 \%$ and in gynaecologic patients $1.47 \%$ had wound infection. There was no urinary or respiratory tract infection, no vault haematoma, pelvic abscess or dehiscence of scar. Only one patient received extra dose of antibiotic because that abdominal hysterectomy lasted for 3 hour and $15 \mathrm{mins}$ and that patient postoperative period went uneventful. There were no intraoperative complications in both obstetric and gynaecologic cases.

The administration single dose prophylactic Cefotaxime is effective in preventing postoperative complications. The results obtained in this study shows single dose antibiotic prophylaxis is as effective as conventional multi dose antibiotic therapy. It is cost effective when compared to multi dose regimen. The resistance of microorganisms can be prevented by use of this single dose prophylactic antibiotic. This prospective study confirms that single dose antibiotic prophylaxis had a beneficial effect on women undergoing elective caesarean section and gynaecologic surgeries.

\section{ACKNOWLEDGMENTS}

Authors would like to thank Dr. Sridevi T. A., for the valuable guidance and support in initiating this study. Author also thank Dr. Vijayaprasad Gopichandran our statistician in helping constantly. Lastly Author indeed grateful to Dr. Mohanavalli Singaram who has been a constant source of inspiration.

\section{Funding: No funding sources}

Conflict of interest: None declared

Ethical approval: The study was approved by the Institutional Ethical Committee No:07/27/10/2014

\section{REFERENCES}

1. Mangram AJ, Horan TC, Pearson ML, Silver LC, Jarvis WR. Guideline for prevention of surgical site infection, 1999. Centers for Disease Control and Prevention (CDC) Hospital Infection Control Practices Advisory Committee. Am J Infect Control. 1999;27:97-134.

2. ACOG Committee on Practice BulletinsGynecology. ACOG practice bulletin No. 104: antibiotic prophylaxis for gynecologic procedures. Obstet Gynecol. 2009;113:1180-9.

3. National Institute for Health and clinical Excellence. 1.4.6.19-20:2011. Review of Clinical Guideline (CG74) - Prevention and treatment of surgical site infection. NICE;2011.

4. Cunningham FG. Cesarean delivery and peripartum hysterectomy. In: Leveno KJ, Bloom SL, Hauth JC, Gilstrap LC, Wenstrom KD, editors. William's obstetrics. 22nd ed. New York: McGraw Hill; 2005:588-604.
5. Kamat AA, Brancazio L, Gibson M. Wound infection in gynecologic surgery. Infect Dis Obstet Gynecol. 2000;8:230-4.

6. McDonald M, Grabsch E, Marshall C, Forbes A. Single- versus multiple-dose antimicrobial prophylaxis for major surgery: a systematic review. Aust N Z J Surg. 1998;68:388-96.

7. Lamont RF, Sobel JD, Kusanovic JP. Current debate on the use of antibiotic prophylaxis for caesarean section. BJOG. 2011;118:193-201.

8. Burke JF. The effective period of preventive antibiotic action in experimental incisions and dermal lesions. Surg. 1961;50:161-8.

9. Liu S, Liston RM, Joseph KS, Heaman M, Sauve R, Kramer MS. Maternal Health Study Group of the Canadian Perinatal Surveillance System. Maternal mortality and severe morbidity associated with low risk planned caesarean delivery versus planned vaginal delivery at term. CMAJ. 2007;176(4):45560.

10. Harbarth S, Samore MH, Lichtenberg D, Carmeli Y. Prolonged antibiotic prophylaxis after cardiovascular surgery and its effect on surgical site infections and antimicrobial resistance. Circulation. 2000;101:291621.

11. Duff P, Park RC. Antibiotic prophylaxis in vaginal hysterectomy: a review. Obstet Gynecol. 1980;55:193S-202S.

12. Tanos V, Rojansky N. Prophylactic antibiotics in abdominal hysterectomy. J Am Coll Surg. 1994;179:593-600.

13. McGregor JA, French JI, Makowski E. Single-dose cefotetan versus multidose cefoxitin for prophylaxis in cesarean section in high-risk patients. Am J Obstet Gynecol. 1986;154:955-60.

14. Chang WC, Lee MC, Yeh LS et al. Quality-initiated prophylactic antibiotic use in laparoscopic-assisted vaginal hysterectomy. Aust N Z J Obstet Gynaecol. 2008;48:592-5.

15. Garner JS. CDC guideline for prevention of surgical wound infections, 1985. Supercedes guideline for prevention of surgical wound infections published in 1982. Infect Control. 1986;7(3):193-200.

16. Gourisankar K, Lall SS, Mukherji J, Roy H, Bhattacharyya SK, Hazra A. A Randomized Controlled Trial Comparing Two Different Antibiotic Regimen for Prophylaxis at Cesarean section. J Obstet Gynecol India. 2012;62(1):35-8.

17. Campillo F, Rubio JM. Comparative study of single dose cefotaxime and multiple doses of cefoxitin and cephazolin as prophylaxis in gynaecologic surgery. Am J Surg. 1992;164(4A Suppl):S12-5.

18. Tita ATN, Rouse DJ, Blackwell S, Saade GR, Spong $\mathrm{Cy}$, Andrews WW. Emerging Concepts in Antibiotic Prophylaxis for Cesarean Delivery: A Systematic Review. Obstetr Gynecol. 2009;113(3):675-82.

19. Cunningham FG, Leveno KJ, Bloom SL, Hauth JC, Gilstrap LC, Wenstrom KD. Single dose antibiotic prophylaxis in elective obstetrics. William Obstetrics 22nd ed. USA: McGraw-Hill Education;2005. 
20. John A, Jones, Howard W. Antibiotic prophylaxis in elective gynecology. Te Linde's Operative Gynecology 9th Ed: Lippincott Williams \& Wilkins;2003:195-207.

21. Schaberg DR. Resistant gram-positive organisms. Ann Emerg Med. 1994;24(3):462-4.

22. Schaberg DR, Culver DH, Gaynes RP. Major trends in the microbial etiology of nosocomial infection. Am J Med. 1991;91(3B):72S-5S.

23. Sadique I, Abid S, Aleem S, Anwar S, Hafeez M, Pasha M. et al. Single Dose Prophylaxis in Obstetrics and Gynecological Surgeries. Annals. 2009;15(4):176-9.

24. Sadaquat Jabeen, Rehena Rahim, Single Dose Versus Multi Dose Cephradine As Antibiotic Prophylaxis In Elective Abdominal Hysterectomy. JPMI. 2007;21(1):50-4.

25. Gonik B. Single versus three dose cefotaxime prophylaxis for caesarean section. Obstet Gynecol. 1985;65(2):189-93.

26. Shaheen S, Akhtar S. Comparison of single dose versus multiple doses of anitibiotic prophylaxis in elective caesarian. J Postgrad Med Inst. 2014;28(1):83-6.

27. Francis C, Mumford M, Strand ML, Moore ES, Strand EA. Timing of prophylactic antibiotic at cesarean section: a double-blinded, randomized trial J Perinatol. 2013;33(10):759-62.

28. Shakya A, Sharma J. Comparison of single versus multiple doses of antibiotic prophylaxis in reducing post-elective cesarean section infectious morbidity. KUMJ. 2010;8:30:179-84.

29. McDonald M, Grabsch E, Marshall C, Forbes A. single-versus multiple-dose antimicrobial prophylaxis for major surgery: a systematic review. Aust N Z J Surg. 1998;68(6):388-96.

30. Noyes N, Berkely AS, Freedman K, Ledger W. Incidence of post-partum endomyometritis following single-Dose antibiotic prophylaxis with either Ampicillin/Sulbactum, Cefazoline, or Cefotan in high risk cesarean section patients. Infect Dis. Obstet Gynecol. 1998;6:220-3.

Cite this article as: Mohan J, Thangaroja T, Menon M. Single dose antibiotic prophylaxis in elective obstetric and gynaecological surgeries-a descriptive study. Int J Reprod Contracept Obstet Gynecol 2017;6:3897-3902. 